\title{
Experimental Learning of Production System Design and Learning Effect Analysis
}

\author{
Yanwen Dong \\ Cluster of Science and Technology \\ Fukushima University \\ No.1, Kanayagawa, Fukushima 960-1296, Japan \\ dong@sss.fukushima-u.ac.jp
}

\author{
Xiying Hao \\ Graduate school of Science and Technology \\ Fukushima University \\ No.1, Kanayagawa, Fukushima 960-1296, Japan \\ kakukiei@yahoo.co.jp
}

\begin{abstract}
Chinese universities and colleges currently offer managementeducation programs, including 115 program of management engineering and 181 program of industrial engineering. However, almost all of the classes were carried out in the classroom and experimental education has not been considered as important. As a result, the students cannot well understand what they learned in the classroom.At almost of Japanese universities, experimental education is considered more serious than Chinese universities, and a large number of experimental subjects are incorporated into their curricula.They are still facing a difficult issue how to train the students to be ready for practical jobsimmediately. In order to enable the students to understand well cellular manufacturing and learn how to design a manufacturing line, alaboratory experiment entitled as industrial system laboratory is offered to the students in Fukushima University.Using LEGO Mindstorms kit, the students can create a variety of mechanical systems and therefore the experiment content is adjustable corresponding to the available learning time and the level of the students. It has the advantages of high adjustability, high flexibility and low cost.From a questionnaire to the students, it is clarified that most of the students of the faculty of science and technology have a potential and/or desire to learn through making something, and the experiment was welcomed by the students and is an effective educational method. Furthermore, through this experiment, we can investigate the impact of human factor such as learning and the aptitude of operators on performance of cellular manufacturing.
\end{abstract}

Keywords-teaching and learning;experimental education; production system;laboratory; human factor

\section{INTRODUCTION}

In response to economic reforms and improvemanufacturing and business efficiency, Chinese universities set about introducing programs related to industrial engineering (IE) and managementsince the 1980s. In 2013, 746 universities and colleges offer management education programs. There are 115 program of management engineering and 181 program of IE. These programsare intended to train professionals familiar with both engineering and management. Their curricula cover the usual areas of operations research,human factors and ergonomics, production systems, logistics, information systems, enterprise financialmanagement, quality management, service engineering, etc. Most of the now commonly used theories and concepts have been educated such as just-in time, lean production, enterprise/manufacturing resource planning, total production management, overall equipment effectiveness, theory of constraints, etc. Despite all these efforts, there are many criticisms of management engineering and IE education, such as weak relationship between education content and career success, low adaptability to practical jobs.One of the reasons for these criticisms is that the students have few opportunities for 'learning by doing' [1][2] [3].

In Japan, IEeducation started very early and the first undergraduate program of industrial management was established in 1943 at Waseda University. In 2013,47 universities and colleges offer59 programs related to IE or management science. Comparing with Chinese management education, the programs related to IE or management scienceat Japanese universities havemany different characteristics. An important differenceis that they consider experimental education more seriously than Chinese universities and their curricula include a large number of experimental subjects. They also take care to make the students to learn some inherent techniques such as information system, mechanical engineering,electrical/electronicengineering, etc. However, the fact remains thatJapanese universities are still facing a difficult issue how to train the students to be ready for practical jobsimmediately.

Moreover, in all countries, developing students' ability is more important than teaching themany knowledge.It is an everlasting issue to look for an effective method to train students to have a higher ability. For this purpose, many efforts have been made to strengthen experimental education. As an effective and convenient method, the experiment subjects have been increased in the curricula of some universities.

In this paper, we describea laboratory experiment entitled as industrial system laboratory, which is offered to the students in Fukushima University. To understand cellular manufacturing and learn how to design a manufacturing line, the students assemble a toy robot work through oneperson cell and a conveyor line respectively, and then, they are required to devise and execute some ideas to improve the operations efficiency. Using LEGO Mindstorms kit, the experiment equipment and parts are available repeatedly and thereforeit has the advantage of low cost and high flexibility. Furthermore, through this experiment, we can investigate the 
impact of human factor such as learning and the aptitude of operators on the performance of cellular manufacturing.

This paper is organized as follows. At first, we introduce the experiment, giving a detailed description of its aim, procedure and a comparison with other experimental subjects. Then we give somestatistics on the students' answers to a questionnaire to demonstrate the effectiveness of the experiment. Furthermore, we givesome investigation results obtianed based onthe measurement data of the experiment. Finally, we give several discussions and concluding remarks.

\section{INDUSTRIAL SYSTEM LABORATORY}

\section{A. Purpose And Outline}

The industrial systemdepartment of Fukushima University was established in 2004. It joins materials science, biotechnology, chemistry and energy science, production and logistics systems, management information engineering, operations research, product development and marketingtogether, and aims at trainingthe students to be an engineer understanding the management or a manager of understanding technology.In order to give the students more opportunities for 'learning by doing', several experimentation experiencesare offered to the students and one of them is the industrial system laboratory [5].

The industrial system laboratory was designed according to the following considerations.

- The main purpose is to enable the students understand cellular manufacturing and production line system, and learn how to design a manufacturing line.Although the students learned the knowledge of production systems through taking two lectures entitled management engineering and production management respectively, the term-end examination showed that they could not understandthe difference between a production line system and a cellular manufacturing system, and they did not know why it is necessary to balance a production line. The students need exercises or practices to experience or confirm the knowledge that they learned in the classroom.

- The experiment contents shouldbe able to be adjusted corresponding to the availablelearning time and the level of the students.To understand production systems by practice, the experimentshould be set to produce a good from some materials and/or parts. AJapanese university offers the students anexperiment of assemblingthe BontenMaru,which is an intelligent one-chip robot in the form of a battery-powered mini-car with two large rubber rear wheels and a smaller plastic front wheel. Another universityoffers the students an experiment of manufacturingIC (Integrated Circuit) chips. As assembling the robot and manufacturingIC chips should follow the operation procedure exactly, the contents and times cannot be adjusted, and therefore, these experimentslack flexibility.Another aim of our experiment is to improve flexibility.

- The experiment shouldbe carried out with a low running cost. When an experiment uses expensive large equipment and/or irreproducible materials/parts, running

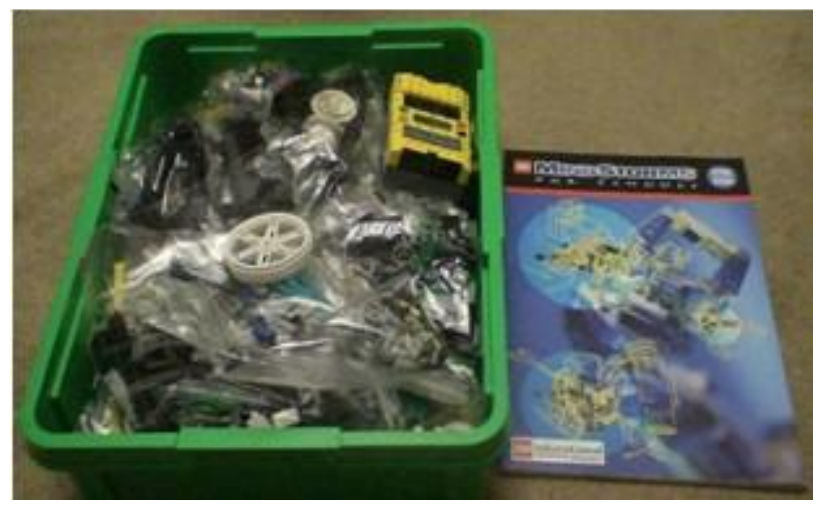

Figure 1. $\quad$ LEGO MINDSTORMS ${ }^{\mathrm{TM}}$ for Schools.

cost is very high. It is desirable to use materials/parts repeatedly and avoid the use of expensiveexperimentequipment.

Based on these considerations, we decided to introduce LEGO MINDSTORMSTM for Schools (Fig. 1).Itoffers a unique and ingenious means of teaching robotics and computer programming to students of various ages, and enables studentsto create small, customizable and programmable robots. This kit includes a programmable brick computer that controls the system, a set of modular sensors and motors, and more than 800 pieces of LEGO parts

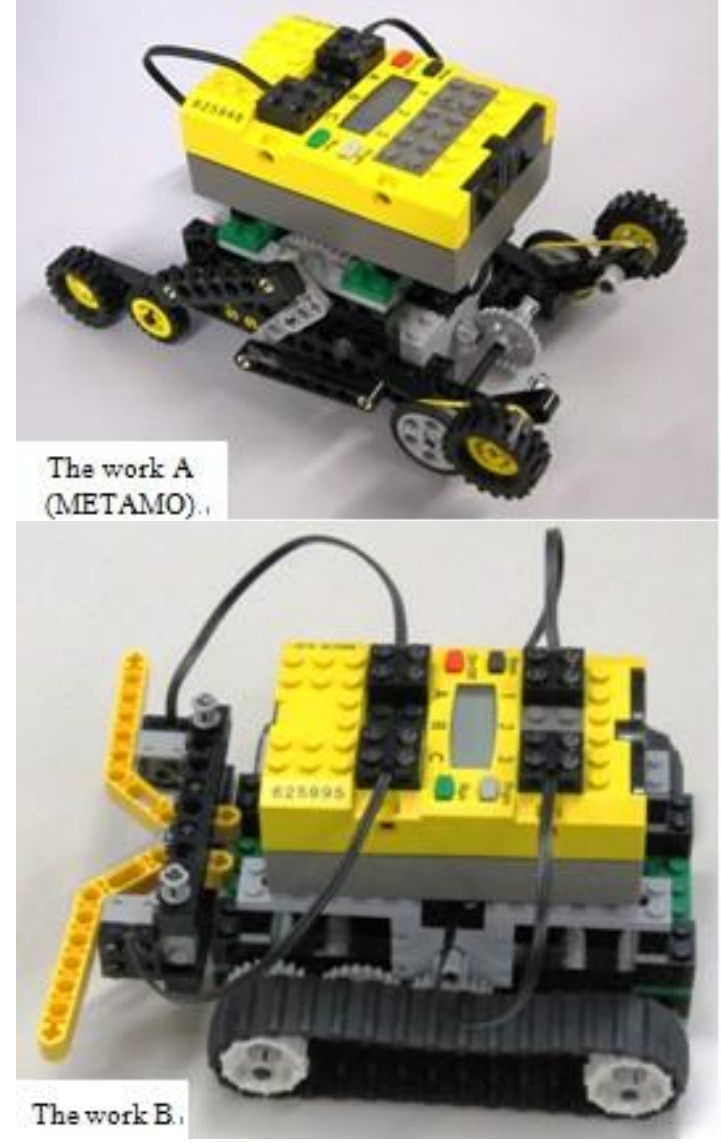

Figure 2. Two works of the experiment 
from the Technics line.Using LEGO Mindstorms kit,the students can build and program real-life robotic solutions, and create a variety of mechanical systems. As shown in Fig. 2, we have adoptedtwo works in our experiment to adjust the learning time. Because LEGO parts can be used repeatedly, the running cost is almost zero.

\section{B. Procedure of The Laboratory}

According the available learning time, we can decide the work to be assembled, and thencarry the experiment out along with the following steps [6-7]:

- [Step 1] Giving some assembly manuals to the students, the teacher demonstrates the assembling tasks of the work through assembling it practically in front of the students. Following the teacher's demonstration, the students learn the sequence and techniques to assemble the work and then assemble one work by oneself.

- [Step 2] Dividing the assembling process into 17 tasks, the students do these assembling tasks by one-person cell (see Fig.3) and measure the operation time of every task.

- $\quad$ Step 3] Based on the operation times measured at the previous step, the students prepare a production line design of 10 workstations. Here the load balance of the line is required and completed by trial and error.

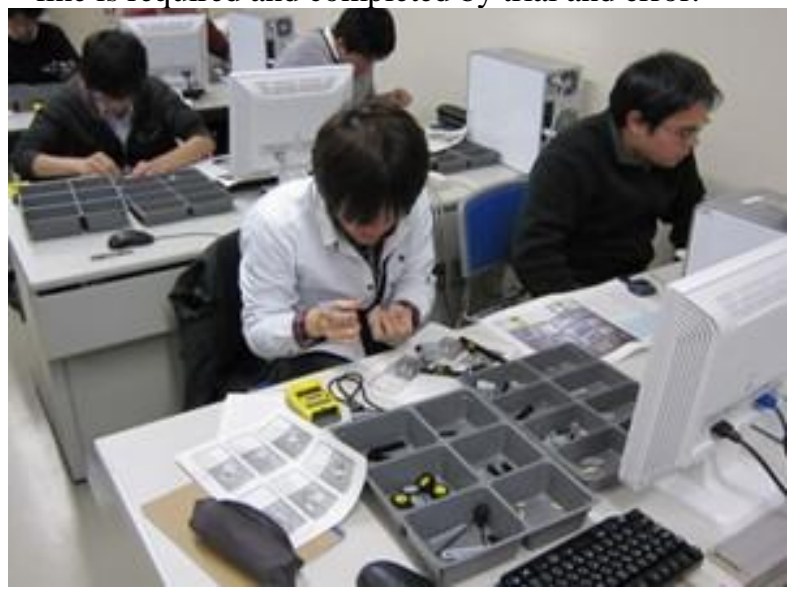

Figure 3. Assembling by one-person cell

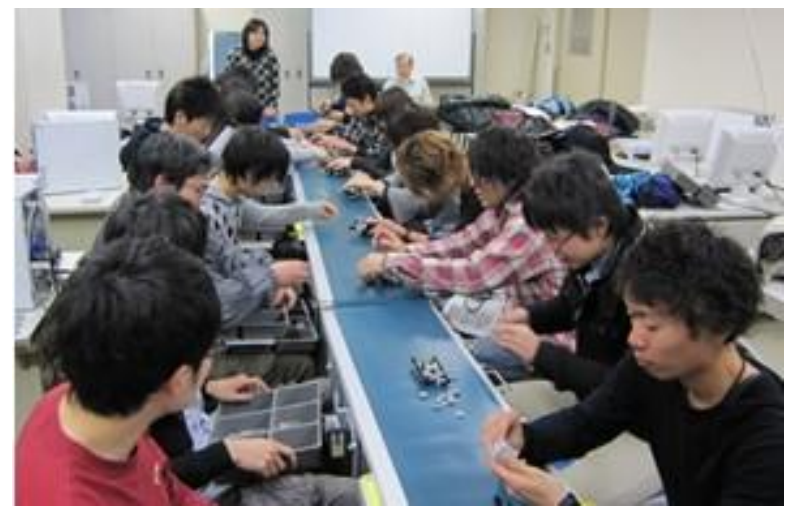

Figure 4. Assembling by production line
- $\quad$ [Step 4] Finally, the students really build a conveyer line to assemble the work and regulate the workload of all the workstations to improve the line efficiency. As shown in Fig.4, when the 10 students are assembling the work as operators, another 10 students play as cooperators and prepare the necessary parts to the operators.

\section{STATISTICS On ThE STUdENTS' EXPERIENCE}

In order to know how the students think about this experiment, we designed a questionnaire and required all students to answer it at the end of theexperiment.The questionnaire sheet consists of 23 questions, and four of them areshown in Table I. These questions are answered by 5-grade scores, score of five meaning the most agreement and score of one meaning the least agreement.

TABLE I. QUESTIONNAIRE

\begin{tabular}{|l|l|}
\hline No & \multicolumn{1}{|c|}{ Question Item } \\
\hline Q1 & All of experiments are my favorite subjects. \\
\hline Q2 & I like to make something. \\
\hline Q3 & This experiment was interesting. \\
\hline Q4 & This experiment was meaningful. \\
\hline
\end{tabular}

\section{A. Attitude of The Students}

Sixty-sevenstudents answered the questionnaire, and 63 of them were valid. The valid recovery rate was $94.0 \%$.In order to evaluate the internal unanimity and reliability of the answers,Cronbach $\alpha$ coefficient is used. Asthe result, the total Cronbach' $\alpha$ value is 0.728 and Cronbach' $\alpha$ value of each question's answerrange from 0.621 to 0.739 . These results indicate that the inner reliability is good enough.

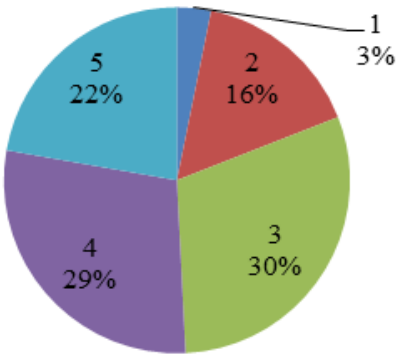

Figure 5. Answers to the question $\mathrm{Q} 1$

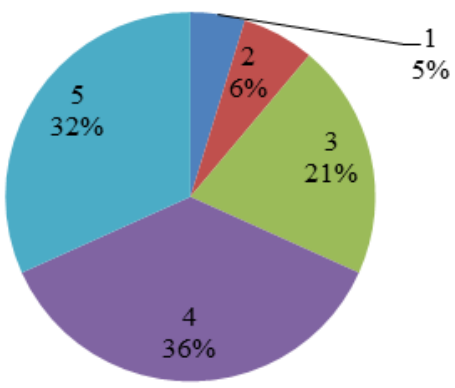

Figure 6. Answers to the question Q2

Fig. 5 and Fig. 6 show the students' answers to the question Q1 and Q2 respectively.Thesetwo questions were 
designed to check the students' attitude on experimentalsubjects. To the Q1 (All of experiments are my favorite subjects), $22 \%$ and $29 \%$ of the students chose score of five and score of four respectively and therefore $51 \%$ ofthe studentsprefer experimentalsubjectsto lectures in classrooms. In addition to this, as shown in Fig. 6, 32\% and $36 \%$ of the students chose score of five and score of four respectively when asking them the question Q2 (I like to make something). It indicates that $68 \%$ of the students like to learn through making something. Considering $21 \%$ of the students chose score of three, it is clear that $89 \%$ of the students, more correctly the students of the faculty of science and technology, do not have antipathy toward making something.

From this result, it is clarified that:

- Most of the students of the faculty of science and technology have a potential and/or desire to learn through making something. About $50 \%$ of the students prefer experimentalsubjectsto lectures in classrooms.

- The experimental subject is welcomed by the students and is an effective educational method.

\section{B. Experience of The Students}

Fig. 7and Fig. 8 show the students' answers to the question Q3 and Q4, these two questions were designed to check the students' feeling ofthe experiment. From Fig. 7, it is clear that $28 \%$ and $49 \%$ of the students chose score of five, score of four respectively to the Q3 (This experiment was interesting). Overall,77\% of the students feltthe experimentinteresting.Furthermore, as shown in Fig. 8, the students choosing score of five, four and threeare $16 \%, 35 \%$ and $41 \%$ respectively when asking them the question Q4 (This experiment was meaningful).These results indicate that:

- The content of the experiment was appropriate and enabled the student to have a large interest in it. In general, the students can learn well that they are interested. Hence, theexperiment provides the studentsan

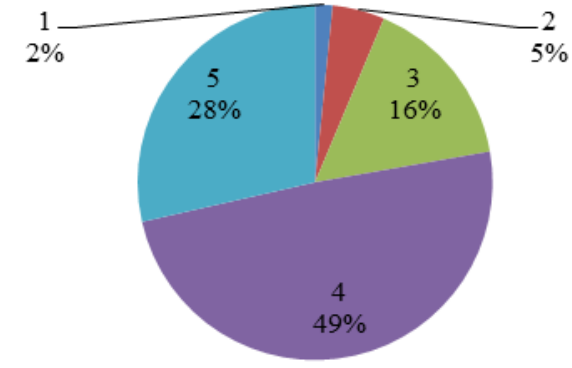

Figure 7. Answers to the question Q3

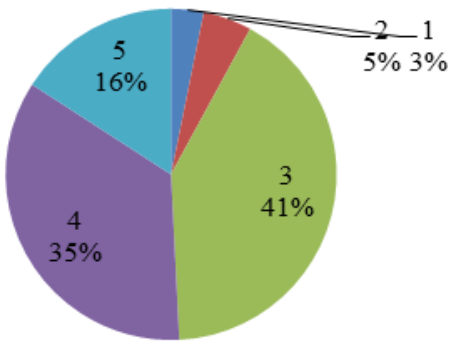

Figure 8. Answers to the question Q4 opportunity to learn production systems by practice.

- More than half of the students considered that they were able to learn something from the experiment. Only $8 \%$ of the students gave the experiment a negative evaluation. It is entirely fairto say that the experiment is an effective subject to train the students' ability of designing production systems.Moreover, the free comment from the studentsalso proved that theexperiment has a comparatively high effect on training the students' ability.

\section{LEARNING EFFECT ANALYSIS}

As the assembly operation is repeated, operators can learn the skills and techniques from experience and then improve graduallythe operation efficiency. To investigate the impact of learning on the operation time,Fig. 9 shows the distribution of time reduction rate from the first experience to the third one [7].The horizontal-axis represents assembly time of the third experience. From Fig. 9, we can observe that:

- As the time reduction rate ranges from $9.1 \%$ to $65.4 \%$, the learning effect through experience changes widely by operators or there is a large difference in the learning ability of operators.

- As shown in the upper right area, although some operators have very high ability of learning, the operation time of the third experience is still longer than others. In contrast with this, some operators (in the lower left area) could complete the assembly within very short time from the first experience and showed a lower reduction rate at operation time.

- As shown in the area enclosed in the circle, there are a few operators who took longer time than others to complete the assembly tasks and could not reduce assembly time conspicuously too. In addition to this, there were four students taking too long time to fulfill assembling and time measurement three times, and their assembly times could not be considered as valid samples, it is obvious that a few operators have a very low aptitude for cellular manufacturing.

From these results, it is clear that operators' aptitude includes two abilities: one is the skill to do the operation

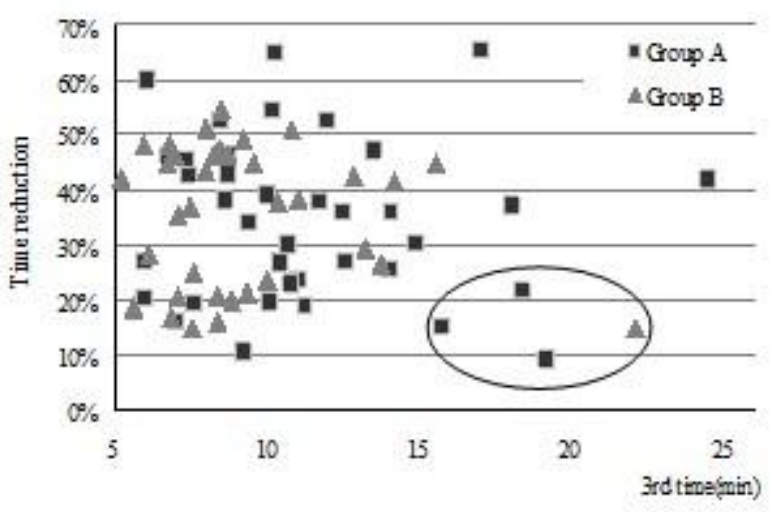

Figure 9. Time reduction and aptitude 
efficiently, and another is the learning ability to improve the operation quickly through experience. Therefore, in order to implement cellular manufacturing successfully, it is necessary to select the workers with higher skill of the operations or ones with higher learning ability to improve the operations quickly.

\section{CONCLUDING REMARKS}

In this paper, we describedan experimental subject entitled as industrial system laboratory.Taking this experiment,the students can understand cellular manufacturing and learn how to design a manufacturing line through assembling a toy robot through one-person cell and a conveyor line respectively. Theexperiment provides the students an opportunity to learn production systems by practice. Using LEGO Mindstorms kit,the students can create a variety of mechanical systems and therefore the experiment content is adjustable corresponding to the availablelearning time and the level of the students. Because LEGO parts can be used repeatedly, the running cost is almost zero.It has the advantagesof highadjustability, high flexibility and low cost.

From a questionnaireto the students, it is clarified that most of the students of the faculty of science and technology have a potential and/or desire to learn through making something, and the experiment was welcomed by the students and is an effective educational method.

Furthermore, through this experiment, we can investigate the impact of human factor such as learning and the aptitude of operators on performance of cellular manufacturing.

\section{ACKNOWLEDGMENT}

This work was partly supported by Grant-in-Aid for Scientific Research (C) from the Japan Society for the Promotion of Science under Grant No. 25380497.

\section{REFERENCES}

[1] Y. Wang,Research on the Development Strategy for Undergraduate Education in Management Science and Engineering Discipline and Its Specialties,PhD Thesis, Tianjin University, Tianjin, P.R.China, pp. 84-89, 2007. (in Chinese).

[2] J.Wang, R. Yan, K. Hollister and D. Zhu, "Ahistoric reviewof management science research in China," Omega,vol. 36,pp. 919 - 932, 2008.

[3] K. Goodall, M. Warner and V. Lang, "HRD in the People's Republic:The MBA 'with Chinese characteristics'?", Journal of World Business, vol. 39, pp. 311-323, 2004.

[4] X. GUAN, S. FENG andM. LOU, "Analysis on Development Direction of the Major of Management Science," Journal of Shandong Institute of Business and Technology,vol. 20, no. 2, pp. 37-39, 2006. (in Chinese)

[5] Y. Dong, H. Haraguchi and M. Yokoyama, "A Study Of Human Factors In Cellular Manufacturing Based On Experiment Results Of Industrial System Laboratory," Proceedings of The tenth International Conference On Industrial Management (ICIM2010), pp.3-7, Beijing, China, Sep. 16-18, 2010.

[6] H. Haraguchi, K. Inoue andY. Dong, "Structural Equation Modelling Of Human Factors And Their Impact On Productivity Of Cellular Manufacturing," The 21th International Conference on Production Research (ICPR21), Stuttgart, Germany, July 31-Aug.4 (2011).

[7] H. Haraguchi and Y. Dong: "An Experimental Study of Human Factors' Impact in Cellular Manufacturing and Production Line System", Proceedings of 2011 Asian Conference of Management Science \& Applications (ACMSA2011), pp.381-389, December 2123, 2011, Sanya, Hainan, China. 